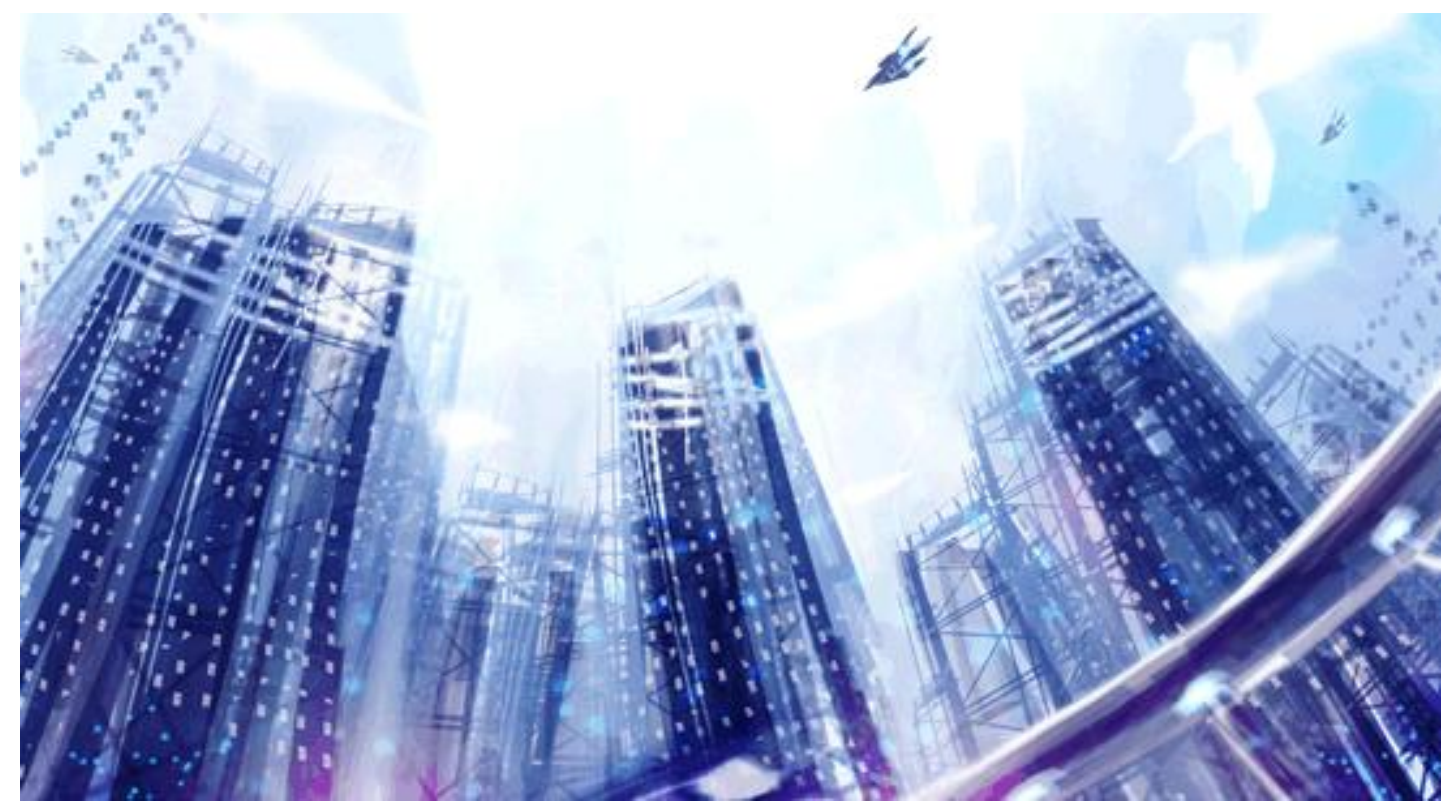

\title{
Cidades de vidro: das galerias de vidro parisienses às galerias das câmeras de vigilância
}

(Glass cities: from the parisian glass galleries to the surveillance cameras galleries)

\section{Eliana Monteiro*}

\section{Resumo}

Esse artigo compara as galerias de vidro parisienses, analisadas por W. Benjamim, com as novas galerias constituídas, atualmente, pelas câmeras de vigilância nos espaços públicos das cidades contemporâneas. Tem como questão central as imagens captadas pelas câmeras nos espaços público e privado e suas inserções nos programas jornalísticos da TV.

Palavras-chave: espaços público e privado; câmeras de vigilância; imagens; televisão.

\section{Abstract:}

This article compares the parisians glass galleries, analised by W. Benjamin, with new galleries, where surveillance cameras become part of the public space in the contemporary cities. It has the images captured by the cameras on the public and private space and their insertion on the TV news as the central question.

Keywords: Public and private space; surveillance cameras; images; television.

\footnotetext{
* Doutora pela Eco - Escola de Comunicação da UFRJ. Professora da UNESA. Endereço postal: Rua
} André Cavalcanti 193 - Santa Teresa - Rio de Janeiro -RJ. E-mail: elianamonteiro@uol.com.br . 
Há, na atualidade, entre o poder e os corpos, um elemento de interação: a imagem. Lembrando Foucault, o corpo, inicialmente supliciado (sociedades de soberania), posteriormente moldado (sociedades disciplinares), hoje, está enfraquecido e o poder passa a ser exercido não apenas sobre a materialidade dos corpos, mas sobre as suas imagens que são produzidas pelas câmeras instaladas nos espaços públicos das cidades e, simultaneamente propagadas nas telas de vidro dos computadores instalados nos centros de captação. Assim, o poder atua não mais tanto sobre o corpo encarnado do indivíduo, mas sim, e especialmente, sobre o espectro deste corpo.

Diante disso, é preciso compreender como se constitui, na atualidade, a relação deste corpo moderno, construído através de um olhar tecnológico, com o poder.

\footnotetext{
Num contexto de digitalização universal, em que uma nova metáfora bioinformática tomou de assalto o nosso corpo, o velho corpo humano (...), já prece obsoleto. Diante da matriz tecnocientífica, onde o ideário virtual vê na materialidade do corpo uma viscosidade incômoda (...), ansiamos pela perda do suporte carnal, aspiramos por uma imaterialidade fluída e desencarnada. (PELBART, 2003, p.46)
}

Esta afirmativa de Pelbart revela a perda gradual de um velho corpo humano e o aparecimento de outro corpo, configurado na sua imaterialidade desencarnada que se constitui através da sua semelhança na imagem.

Veja-se como esse processo ocorre hoje e como ele aparece na TV. Primeiramente se explicite uma nova visão do espaço urbano onde estão sendo construídas galerias vigiadas pelas câmeras. Tais câmeras vigiam o fluxo dos corpos; sua função primeira não é identificar, mas gerir fluxos.

\section{ESPAÇO URBANO: GALERIAS DE VIDRO}

Com a inserção, cada vez mais comum, das imagens dos vídeos de vigilância nos programas jornalísticos, o telejornalismo brasileiro passa a ganhar uma nova configuração e, consequentemente, o olhar do espectador é submetido a ela; diante dele, um acontecimento em pleno andamento, ocorrendo no seu próprio tempo de duração. Esta experiência visual quase cotidiana exercita também o espectador a um tipo de olhar que se aproxima do olhar dos agentes de vigilância, aqueles que ocupam as centrais de captação das imagens vigiando as ações que se desenrolam nos espaços públicos. Isto porque, como já se disse anteriormente, são imagens que se caracterizam inicialmente para uso comprobatório das transgressões praticadas nestes espaços e não como imagens meramente informativas. 
Essas imagens, ao serem exibidas nos telejornais, expandem este olhar de vigilância a um grande público. Deste modo, o espectador parece experimentar na atualidade a passagem de um olhar treinado pela televisão clássica para um outro olhar que surge com o uso dos novos dispositivos tecnológicos de visibilidade -, capaz de tirar esse espectador do lugar confortável de assistente do acontecido para o lugar de vigia do acontecendo. Este processo conduz o espectador a fazer novas leituras dos espaços públicos da cidade que são marcados pelas câmeras de vigilância.

Quando Benjamin fala sobre as Passagens construídas em Paris, no ano de 1852, as descreve como

(...) galerias cobertas de vidro e com paredes revestidas em mármore que atravessam quarteirões inteiros (...). Em ambos os lados dessas galerias, que recebem luz do alto, alinham-se as lojas mais elegantes, de modo que tal passagem é uma cidade (...). São elas o refúgio para todos que são pegos desprevenidos. Garantindo um passeio seguro, porém restrito, do qual os comerciantes também tiram suas vantagens. (BENJAMIN, 2006, p.77-78)

Assim como as passagens envidraçadas construídas na cidade de Paris ao final do século XIX anunciavam aos seus moradores e visitantes uma cidade em processo de transformação arquitetônica, as câmeras de vigilância hoje espalhadas nas principais ruas e avenidas dos grandes centros urbanos parecem anunciar de certa maneira, através de seus corredores formados por suas lentes de vidro invisíveis, as novas passagens do século XXI. Deste modo, a arquitetura urbana atual, ao integrar-se a uma topologia eletrônica, perde uma inscrição espacial anterior e passa a se constituir "nas sequências de uma planificação imperceptível do tempo na qual a interface homem/máquina toma o lugar das fachadas dos imóveis, das superfícies dos loteamentos” (VIRILIO, 1993, p.10). Virílio diz ainda que:

A representação da cidade contemporânea, portanto, não é mais determinada pelo cerimonial da abertura das portas, o ritual das procissões, dos desfiles, a sucessão de ruas e das avenidas: a arquitetura urbana deve, a partir de agora, relacionar-se com a abertura de um "espaço- tempo tecnológico". Op. Cit.)

A cidade de Nova York parece ser um bom exemplo da existência destas passagens. Recentemente foi divulgado que Nova York (MARTINS, 2007, p.27) (hoje 
com seis mil câmeras de vigilância) será a primeira cidade nos EUA, a ser observada por um sistema de vigilância, ligado diretamente ao Departamento de Polícia. Só ao sul da ilha de Manhattan serão mais de cem câmeras de alta definição que vão integrar o sistema, para vigiar, especialmente, pedestres que transitarem nas ruas próximas à Wall Street, área crítica da economia americana. Ainda segundo divulgação, o projeto chamado de Lower Manhattan Initiative prevê também a instalação de mais três mil câmeras de vigilância pública e privada, na área sul de Canal Street até o ano de 2010, garantindo, desta maneira, corredor seguro. Isso lembra Benjamin comentando as passagens de Paris: elas constituem "um passeio seguro, porém restrito do qual os comerciantes também (e no caso, principalmente), tiram vantagens”. Já naquela época, o filósofo classificava estas "passagens" como "outras cidades" existentes dentro da cidade de Paris: "Em ambos os lados dessas galerias, que recebem luz do alto, alinhamse as lojas mais elegantes, de modo que tal passagem é uma cidade". (BENJAMIN, Op.Cit.)

Desde logo, chama-se a atenção para o fato de que, ao se apossar do conceito de passagens em Benjamin e o deslocar das galerias parisienses para o alinhamento das câmeras de vigilância afixadas no alto das construções nos espaços públicos da cidade atual, não se vê impedimento em reafirmar que tanto em Paris daquela época quanto na cidade de Nova York de hoje, as "passagens tecnológicas" foram e são geográfica e estrategicamente "construídas" em locais de grande concentração financeira.

No caso da cidade americana, estão os grupos que articulam grande volume de capital e no caso de Paris, alinham-se as lojas mais elegantes. Podemos dizer que no Brasil a maior concentração destas passagens também se localiza em áreas de grande movimentação financeira às quais integram, na sua maioria, grandes redes internacionais de hotéis e lojas comerciais de luxo. Regiões protegidas por galerias de vidro. Essas novas passagens trazem consigo uma face do horror.

\section{REFLEXOS E TRANSPARÊNCIAS: A INTERFACE DO HORROR}

As ações transgressoras capturadas por essas câmeras que formam as "passagens envidraçadas" dos centros urbanos chegam às telas da televisão, em especial, aos programas jornalísticos. Para falar sobre elas, tome-se uma fábula indiana (Di TELLA, 2005, p.81). 
Ela conta que um homem terrivelmente feio, ao atravessar o deserto a pé, vê algo que brilhava na areia. Era um pedaço de espelho. O homem se ajoelhou, pegou o espelho e olhou. Nunca antes tinha visto um espelho:- Que horror! - exclamou. Não espanta que o tenham jogado fora! Largou o espelho e continuou seu caminho.

Façam-se algumas leituras sugeridas pela fábula, tentando compreender o horror expresso pelo personagem ao defrontar-se com o espelho. Este provém do fato dele ver sua imagem e não a reconhecer. Ele não se reconhece, o espelho para ele não reflete, mas mostra algo do mundo.

De início, é preciso dizer que o espelho é um vidro que tem em seu interior o nitrato de prata, material capaz de produzir reflexos, no caso da fábula, o reflexo do homem que o encontrou. O vidro, ao contrário, age exatamente pela ausência do nitrato, logo não é um material reflexivo, isto é, uma pessoa, ao se colocar diante de um vidro, terá transparências e não reflexos, logo, não se vê, mas é capaz de ver o outro.

Benjamin, ao falar das paredes de espelhos, que revestem os cafés parisienses, lembra que elas revelam aos que passam nas ruas, as mercadorias que se encontram dispostas à direita e à esquerda nas prateleiras afixadas no interior destes estabelecimentos: "o revestimento de espelhos das paredes conduz a imagem do mundo interior para o exterior", o vidro ao contrário, diz ele: "conduz a imagem do exterior para dentro do mundo interior." (BENJAMIN, 2006, p. 579-583)

Ao que parece, na atual fase da modernidade, os espelhos foram retirados das paredes, em seu lugar foram colocadas as lentes de vidro das câmeras de vigilância voltadas não mais para refletir, como convém aos espelhos, mas sim para dar transparência, através de suas lentes de vidro, às ações imprevisíveis que possam ocorrer no mundo, e que talvez sejam posteriormente mostradas na tela da televisão. O horror provém dessa incapacidade de refletir, onde não mais me reconheço naquilo que vejo, não consigo dar significação ao percebido, não o identifico. A perda dos espelhos traz consigo a perdas das identidades.

Roland Barthes, ao falar das fotografias, faz referência àquelas que retratam mortes violentas e catástrofes, segundo ele, são fotografias que trazem com elas "imagens traumáticas":

O trauma é precisamente o que suspende a linguagem e bloqueia a significação. (...). As fotografias propriamente traumáticas são raras, porque, em fotografia, o trauma é inteiramente tributário da certeza que a cena realmente teve lugar: era necessário que o fotógrafo 
estivesse lá. (grifo original) (...). A fotografia traumática (incêndios, naufrágios, catástrofes, mortes violentas, colhidas "ao vivo") é aquela que nada há a dizer. (BARTHES, 1969, p.313)

As imagens dos vídeos de vigilância que chegam às telas da televisão parecem se espelhar nas imagens traumáticas descritas por Barthes capazes de colher ao vivo o horror do instante. Uma dessas imagens, por exemplo, foi a do assassinato de um vigia em um posto de gasolina no município de Duque de Caxias, em fevereiro de 2007, quando um policial dispara dois tiros contra o homem que morre na hora. Essas imagens não são, pura e simplesmente, um registro informativo com o qual trabalham as produções dos telejornais, ganham outra dimensão narrativa propiciada pelas câmeras de vigilância: elas tornam-se obscenas ${ }^{1}$.

Parte-se do princípio de que estas imagens são potencial e intensamente mais fortes do que aquelas comumente produzidas pelos telejornais, nas quais o instante em que se deu o crime seria reconstituído jornalisticamente através dos vestígios deixados no local e das narrativas das testemunhas. No caso dessas imagens da morte violenta do vigia no posto de gasolina, nada há a dizer. São imagens que rompem, portanto, com os limites visuais com os quais o espectador está habituado. Diante dele, surge a visibilidade total do acontecimento, ao contrário das imagens produzidas nos telejornais, onde havia um tipo de cegueira em relação ao acontecimento. As novas imagens transportam o espectador para um outro campo de visão ao desvendar para ele uma sociedade onde o horror é explícito.

Mais recentemente, imagens de um trágico acidente filmado pelas câmeras de vigilância do Aeroporto de Congonhas em São Paulo ganharam exaustivamente as telas da televisão: um avião que partira de Porto Alegre na tarde do dia 17 de julho de 2007, identificado como vôo 3054, com destino à capital paulista, ao tentar pousar, desliza, em grande velocidade pela pista e, sem conseguir parar, acaba batendo e explodindo sobre um prédio localizado numa avenida próxima ao aeroporto, levando à morte cerca de duzentas pessoas.

\footnotetext{
${ }^{1}$ Utilizamos aqui o conceito de obscenidade de Braudrillard: “(...) quando se está na obscenidade, não há mais cena, jogo, o distanciamento do olhar se extingue. (...). O que vale para os corpos é igualmente válido para a mediatização de um acontecimento, para a informação. Quando as coisas se tornam demasiadamente reais, quando elas são dadas imediatamente, quando existem como realidade concreta, quando estamos nesse curto-circuito que faz com que as coisas se tornem cada vez mais próximas, estamos na obscenidade (...). Há escaladas na obscenidade: apresentar o corpo nu pode ser já grosseiramente obsceno, mas apresentá-lo descarnado, esfolado, esquelético, o é ainda mais." BAUDRILLARD, Jean. Senhas. Rio de Janeiro: DIFEL, 2001, p. 29-30.
} 
O vídeo mostra o instante exato em que o avião toca a pista e os três segundos seguintes em que a aeronave desliza em direção ao seu final para, em seguida, chocar-se contra o prédio próximo ao aeroporto; neste momento avista-se na tela o clarão da explosão. São imagens que além de trazerem ao espectador a "certeza de que a cena aconteceu", dão transparência, através do seu fluxo, a "como ela aconteceu".

"Poderia se imaginar uma espécie de lei: quanto mais o trauma é direto, tanto mais difícil é a conotação; ou ainda: o efeito "mitológico de uma fotografia é inversamente proporcional á seu efeito traumático." (BARTHES, Ibidem)

Deste modo, a cada exibição destas imagens, o espectador é transportado ao presente - vivo direto da tragédia, constituído na sequiência temporal intrínseca ao interior da própria tragédia (antes do clarão da explosão, o avião percorre velozmente a pista por três segundos), portanto a cada exibição, a tragédia se repete, se perpetua, inexoravelmente e nada há a fazer nem a dizer.

Há, porém, diferenças fundamentais entre as imagens traumáticas fotográficas mostradas por Barthes e as imagens traumáticas capturadas pelas câmeras de vigilância: a primeira, para ser capturada, exige que o fotógrafo estivesse no local e no instante do acontecimento, enquanto que a segunda exige apenas a presença da câmera. Muito embora as duas sejam mediadas por câmeras, elas se caracterizam de modos diferentes: uma através do olhar do fotógrafo que faz a "leitura" da cena no momento de sua captura, enquanto que na outra a "leitura" é banida, indicando ao espectador a ausência de um olho leitor no momento de sua captação. Portanto o que o jornalismo televisivo na atualidade está fundando, ao inserir estas imagens nos telejornais, é criar aos olhos do espectador uma rotina de "ver" através daquilo que não era visto. A questão, portanto, que se apresenta não é mais tanto saber de que maneira a realidade cotidiana é retrabalhada nas ilhas de edição antes de chegar às telas da televisão, mas sim, o que esta sendo ocultado.

\section{O OLHO OBSERVADOR: IDENTIDADE E FLUXO}

As imagens das câmeras de vigilância, ao passarem ao largo da leitura da cena, colocam o espectador de TV em contato com outra visibilidade do mundo. Um dos principais aspectos desta nova configuração está na ruptura do olhar tradicional em que, ao captar a cena, o indivíduo toma como referência a relação do seu olho com os olhos dos personagens envolvidos nela, isto é, a cena é capturada a partir da altura de quem 
olha e de quem é olhado. Sendo assim, podemos dizer que a imagem tradicionalmente capturada pelo fotógrafo ou cinegrafista, tinha como primeira função identificar aqueles que estavam diretamente envolvidos na cena:

durante todo o século XIX (e início do XX) a fotografia foi usada tanto como meio de identificação quanto meio para reunir evidências do crime. A coleção de retratos de criminosos presos começou logo após a invenção da fotografia (...). A apreensão de criminosos (...), quase sempre dependeu de seu reconhecimento nessas fotografias. (GUNNING, 2004, p.33)

A imagem fotográfica criminal, portanto, busca desde sua origem identificar fisionomicamente os indivíduos e para isso as fotos eram afixadas nas rougues galleries, (Ibidem, p.43) espaços (montados pelo departamento de polícia francesa) onde eram expostas publicamente as coleções de fotos dos "malfeitores e foragidos" da lei. ${ }^{2}$

A exibição pública de retratos de criminosos profissionais (que buscavam anonimato e segredo) tornou-se uma das formas mais populares de galerias fotográficas, com pessoas afluindo a elas como se fossem pontos turísticos da cidade (...). (Ibidem)

Desse modo, talvez se possa traçar um paralelo entre a exibição das fotos dos criminosos expostas nas galerias e que, devido ao grande número de visitantes, ganhavam popularidade, e as imagens das ações criminosas captadas hoje através das câmeras de vigilância, e que se tornam populares aos serem expostas, a uma grande audiência, através da tela da TV. Em ambos os casos, há grande afluência de público: nas antigas galerias para ver os rostos dos criminosos e na televisão para ver as ações deles.

Há, porém, uma diferença entre as primeiras intenções da fotografia e as imagens de vigilância: enquanto a fotografia buscava a identidade do criminoso, a segunda busca inicialmente a sua ação criminosa. Gunning (Ibidem, p.37) conta que a

\footnotetext{
2 É bom observar que os registros fotográficos destes indivíduos não eram realizados facilmente pelo departamento de policia, os criminosos resistiam com vários mecanismos ao registro de suas imagens. Eles (como relata Gunning, em O retrato do Corpo Humano: a fotografia, os detetives e os primórdios do cinema que pousavam, para estes retratos) "distorciam suas expressões faciais na esperança de impedir a identificação das fotografias (...) fazendo caretas bizarras". Hoje a resistência à identificação dos traços fisionômicos dos indivíduos passa pelo uso de capuz que encobrem as laterais da face ocultando o seu reconhecimento bem como o uso das "máscaras ninjas" (toucas que deixam somente os olhos descobertos).
} 
fotografia, na época, agia como mediadora entre uma imagem privada e pública, e pode, portanto,

ser usada como garantia de identidade e como meio de determinar culpa ou inocência. Em sistemas de poder e autoridade, as possibilidades de circulação da fotografia também puderam desempenhar um papel regulador, mantendo um senso do singular e do reconhecível (...) a fotografia fornece um meio para se apropriar da fisicidade de um fugitivo (...). (Ibidem, p.38)

Nesses termos, fala, ainda, Gunning, a fotografia passa ser a ferramenta ideal para o processo de investigação policial por dois aspectos: primeiro pela sua condição de índice, que vai derivar do fato de que a fotografia resulta da exposição a uma entidade preexistente, isto é, ela mostra diretamente a marca da entidade e pode, portanto, fornecer evidência sobre o objeto que retrata; em segundo lugar por seu aspecto icônico, pelo qual produz uma semelhança direta com seu objeto o que permite um reconhecimento imediato além, de sua natureza separável, o que vai lhe permitir referir-se a um objeto ausente estando separada dele em espaço e tempo. Deste modo, conclui o autor, "a fotografia torna-se parte de um novo discurso do poder e controle".(Ibidem)

Já as câmeras de vigilância registram a ação criminosa no espaço e no tempo, para somente em seguida buscar a identificação do criminoso. Nesse caso, o exercício do poder se investe de uma outra prática de controle: primeiro a cena, depois o seu autor. Deste modo, pode-se dizer que as câmeras, ao serem afixadas no alto dos edifícios, postes e muros dos espaços públicos, sobre as cabeças dos indivíduos, buscam a total visibilidade das ações criminosas, ao contrário das lentes das máquinas fotográficas que se posicionam na altura dos olhos dos criminosos buscando a sua identificação.

Neste caso fica evidente que as marcas do crime na sociedade atual se expressam inicialmente, através do seu espetáculo (as ações do crime sequencialmente exibidas nas telas da televisão), e não mais na imagem/reflexo do criminoso. Sendo assim, o espetáculo torna-se, na sociedade moderna, como nos diz Debord, a sua principal produção: “Ao analisar (grifo no original) o espetáculo, fala-se de certa forma a própria linguagem do espetáculo, ou seja, passa-se para o terreno metodológico dessa sociedade que se expressa pelo espetáculo (...) é o momento histórico que nos contém.” (DEBORD, 1997, p.16,17) 
No caso específico do uso das câmeras de vigilância, o espetáculo se configura no deslocamento da lente do ângulo frontal dos personagens, envolvidos na cena, para um ângulo geral capaz de dar visibilidade à ação privilegiando, deste modo, o fluxo dos corpos e suas ações e não suas identidades.

Há, porém, aqueles malfeitores e foragidos que, ao tomarem consciência da existência das câmeras, encenam para as suas lentes ações do mais alto grau de exibicionismo. Anderson Pereira do Nascimento de 27 anos é um desses casos. O rapaz, segundo a reportagem (ASSALTANTE..., 2007, p. 17) cujo título é Assaltante exibicionista é preso, acompanhado do subtítulo criminoso sorria para circuito interno de $T V$, vinha sistematicamente assaltando uma rede de drogarias na cidade do Rio de Janeiro e tinha como hábito, a cada assalto, mostrar sorrindo a sua arma para as câmeras de vigilância do circuito interno dos estabelecimentos. Nascimento, por deixar-se identificar, acabou preso.

\section{Assaltante exibicionista é preso}
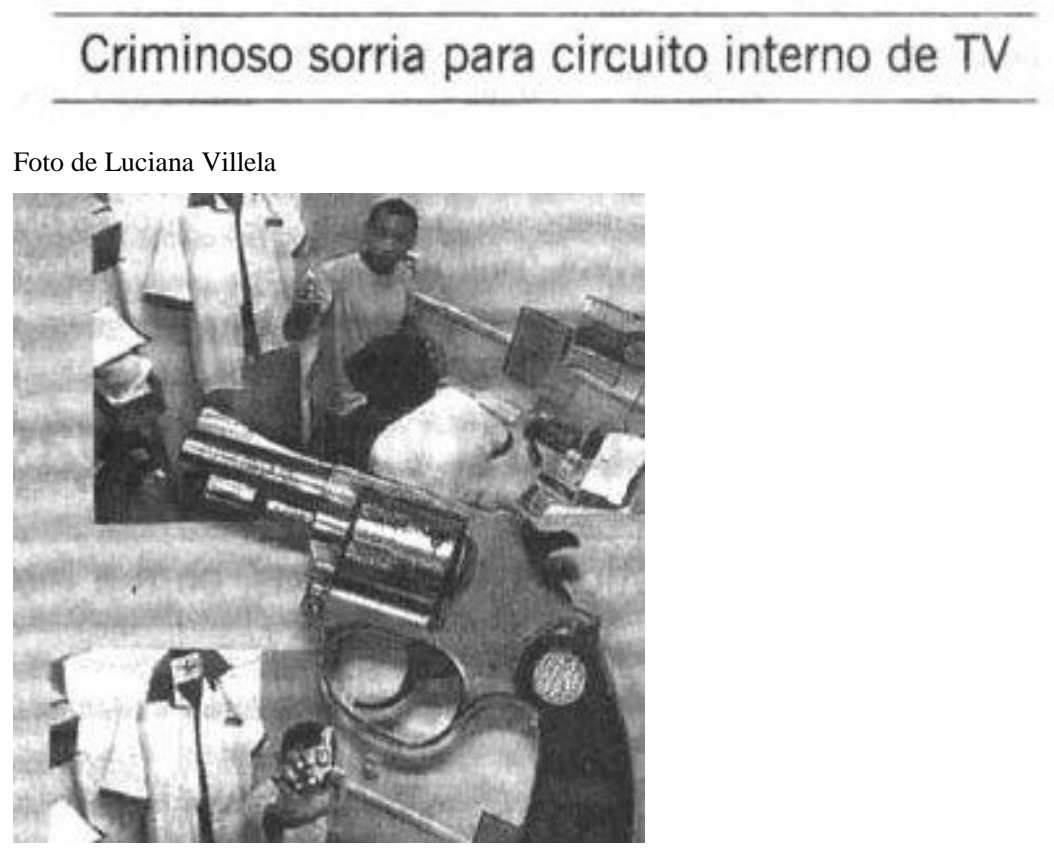

As imagens gravadas do assaltante e sua arma

Esse fato nos leva a observar que alguns indivíduos, ao tomarem consciência de que seus movimentos estão sendo registrados pelas lentes das câmeras de vigilância, são capazes de encenar através de uma estética corporal (sorrir e mostrar a arma) um espetáculo privado produzido especialmente para os olhos daqueles que os observam. 
Muniz Sodré (1984, p.9) conta que um jovem engraxate da favela da Rocinha, ao ser indagado por uma pesquisadora sobre o que gostaria de ver na tela da televisão, responde: "eu". No texto, Sodré faz uma reflexão sobre a natureza da televisão e interpreta a resposta do entrevistado como uma manifestação do desejo de um espectador insatisfeito com a oferta da grade de programação do veículo para, em seguida, dizer que o jovem desejaria ver a si mesmo na tela da televisão, ver a sua própria imagem "refletida nesse moderno espelho eletrônico e por ele multiplicada com tal intensidade que alguma modificação viesse a ocorrer no seu estatuto social de engraxate da Rocinha ou que algo pudesse compensar uma provável auto-imagem negativa"(Ibidem).

No caso de Nascimento, o ato exibicionista parece fazer parte, num primeiro momento, da reação natural de alguns indivíduos ao se verem diante de uma lente de câmera: se comunicar com ela. Assim, Nascimento fez o que é comum em muitos casos fazer, se exibir para a lente, o que, na situação em que ele se encontrava, assaltando uma drogaria, não deixa de surpreender. Desse modo, o assaltante, mesmo correndo o risco de ter sua identidade revelada, busca uma proximidade com a câmera, ação que tripudia, e ele sabe disso, com os indivíduos que estariam vigiando, através da imagem, o estabelecimento comercial. Dessa maneira, Nascimento parece se importar menos em manter o anonimato do que em produzir um pequeno espetáculo exibicionista para os olhos do poder que o observa. A ação do assaltante que não resiste em se exibir para a câmera (tal qual o jovem engraxate que desejaria ver a si mesmo enquanto indivíduo concreto na tela da televisão) demonstra as raízes profundas da fascinação que a lente exerce sobre o homem contemporâneo.

A história da relação da lente da máquina fotográfica com os criminosos nos fala exatamente de ações contrárias às do Nascimento. Os malfeitores e foragidos da época que posavam para a polícia para esses retratos

distorciam suas expressões faciais na esperança de impedir a identificação das fotografias. (...). Era preciso apenas contorcer brevemente a face para criar uma fotografia grotesca. (...). Diversas fotografias incluídas no "museu do criminoso" de Gustave Mac (uma coleção de retratos publicada em 1890) mostram criminosos fazendo caretas bizarras. 'GUNNING, 2004, p.44)

Hoje muitos dos criminosos, mesmo sabendo da existência das câmeras de vigilância na maioria dos estabelecimentos comerciais, não se privam de praticar os assaltos. Durante a ação procuram somente ocultar suas identidades. As caretas bizarras 
foram substituídas em seu lugar pelas máscaras ninja, bonés, óculos escuros etc., ferramentas modernas para a não identificação. A ação criminosa, no entanto, se desenvolve num espetáculo imagético onde a principal preocupação dos criminosos não é ocultar o crime do olho do poder, mas, como ocorria com as antigas fotografias tiradas pelos departamentos policiais de Paris, ocultar as identidades daqueles envolvidos nele.

Nesses termos, a relação desses indivíduos com as câmeras de vigilância se constitui, como se disse anteriormente, na exposição das ações criminosas para esse olho. A própria localização dos dispositivos, no alto sobre as cabeças dos indivíduos, estabelece de certa maneira uma relação com a cena e não com as suas identidades. Sendo assim, pode-se dizer que Nascimento, o assaltante da drogaria, a despeito de revelar a sua identidade, parece saber disso quando sorri e exibe sua arma para uma das câmeras de vigilância do circuito interno de TV instalada estrategicamente no interior do estabelecimento comercial.

Esse seria apenas um dos aspectos desse novo dispositivo de poder: o de vigiar as imagens dos corpos dos indivíduos em ação para posteriormente buscar suas identidades. Os malfeitores e foragidos atuais parecem já ter se ajustado a esse novo sistema de vigilância onde o corpo é apreendido primeiro, para depois buscar-se a sua identificação. Nesse caso, as câmeras de vigilância, ao se apoderarem desses corpos, obtêm primeiro a confissão do crime para depois processar a sua identificação.

Sendo assim, o exercício do poder moderno busca "fixar uma imagem de culpa: o corpo pego no ato" (Ibidem, p.53) de seu crime.

Nesses termos, as câmeras de vigilância agem como "testemunha ocular" de um crime em plena ação e nesse caso não há espaço para a mentira. Não existe, portanto, a possibilidade de um indivíduo ser falsamente acusado já que a câmera captura o acontecimento $^{3}$.

Surge aí uma nova dinâmica, não só na relação entre a televisão e seus espectadores, mas, e principalmente, entre criminosos, a lente das câmeras e os espaços público e privado.

\footnotetext{
3 “As imagens gravadas por câmaras de vídeo vigilância, desde que colocadas legalmente na rua, constituem prova válida em tribunal para uma eventual condenação. Pelo menos é esta a regra prevista na lei. Desde que a Comissão Nacional da Proteção de Dados dê o seu aval e desde que seja esse meio o mais adequado para a manutenção da segurança, ordem pública e para a prevenção da prática de crimes e tendo em conta as circunstâncias". Mas a verdade é que a decisão de aproveitar este meio de prova em tribunal para uma eventual condenação está inteiramente nas mãos de um juiz. In: IN VERBIS - Revista Digital de Justiça e Sociedade. Disponível em: http://www.inverbis.net/tribunais/validade-imagens.html. Acesso em: 25 mar. 2009.
} 


\section{REFERÊNCIAS BIBLIOGRÁFICAS}

BARTHES, Roland. A Mensagem Fotográfica In: LIMA, Luiz Costa (Org). Teoria da Cultura de Massa. Rio de Janeiro: Saga. 1969.

BENJAMIN, Walter. Passagens. São Paulo: Imprensa Oficial do Estado de São Paulo. 2006.

DI TELLA, Andrés. O documentário e eu. In: MOURÃO, Maria Doria; LABAKI, Amir. (Org.). O Cinema do Real. São Paulo: Cosac Naify. 2005.

GUNNING, Tom. O retrato do corpo humano: a fotografia, os detetives e os primórdios do cinema. In: CHARNEY, Leo; SCHWARTZ, Vanessa R. (Org.). O Cinema e a Invenção da Vida Moderna. São Paulo: Cosac Naify. 2004.

ASSALTANTE exibicionista é preso: criminoso sorria para circuito interno de TV. $O$ Globo. 27 de agosto de 2007, p.17.

MARTINS, Marília. Nova York Vigiada. O Globo. Caderno Mundo, p.27, 10 de julho de 2007.

PELBART, Peter Pal. Vida Capital: ensaios de biopolítica. São Paulo: Iluminuras. 2003.

SODRÉ, Muniz. A Máquina de Narciso. Rio de Janeiro: Achiamé. 1984.

VIRILIO, Paul. O Espaço Crítico. Rio de Janeiro: Ed. 34. 1993. 


\section{Para citar essa obra:}

MONTEIRO, Eliana. Cidades de vidro: das galerias de vidro parisienses às galerias das câmeras de vigilância. RUA [online]. 2010, no. 16. Volume 2 - ISSN 1413-2109

Consultada no Portal Labeurb - Revista do Laboratório de Estudos Urbanos do Núcleo de Desenvolvimento da Criatividade

http://www.labeurb.unicamp.br/rua/

\section{Laboratório de Estudos Urbanos - LABEURB}

Núcleo de Desenvolvimento da Criatividade - NUDECRI

Universidade Estadual de Campinas - UNICAMP

http://www.labeurb.unicamp.br/

Endereço:

Rua Caio Graco Prado, 70

Cidade Universitária "Zeferino Vaz" - Barão Geraldo

13083-892 - Campinas-SP - Brasil

Telefone/Fax: (+55 19) 3521-7900

Contato: http://www.labeurb.unicamp.br/contato 